\title{
Displaced intracapsular neck of femur fractures: dislocation rate after total hip arthroplasty
}

\author{
Shituleni $\mathrm{S}^{1}$, Maqungo $\mathrm{S}^{2}$ \\ 1 MD, FC Orth(SA), MMed Ortho(UCT); Specialist orthopaedic surgeon, Orthopaedic Trauma Service, Department of Orthopaedic Surgery, \\ University of Cape Town \\ 2 MBCHB, FC Orth(SA), MMed Orth(UCT); Professor and Head: Orthopaedic Trauma Service, Department of Orthopaedic Surgery, University \\ of Cape Town
}

Corresponding author: Dr Sibasthiaan Shituleni, PO Box 27222, Windhoek, Namibia, 9000; email: shituleni@gmail.com

\begin{abstract}
Background: Dislocation is one of the most common orthopaedic complications after primary total hip arthroplasty (THA). The reported dislocation rate in elective THR is 5-8\%. This number increases up to $22 \%$ for THA done for neck of femur (NOF) fractures. Larger femoral head sizes increase the head-neck ratio and range of motion before impingement, therefore reducing the dislocation rate. Due to the reported increase in dislocation for trauma, some surgeons prefer to do a hemiarthroplasty or open reduction and internal fixation (ORIF) rather than a THA.

Methods: A retrospective review of all THAs done for NOF fractures during 2006 to 2012 was undertaken at a large referral hospital. Records were reviewed for patient-related and surgical risk factors. We excluded all pathological fractures, extra-capsular fractures and failed ORIF.

Results: A total of 92 cases were identified as suitable for analysis. Average age at surgery was 73.2 years (range 30-81). Delay to surgery was 5.3 days (range 1-63). Average follow-up period was 18.3 months (range 3 months to 4.3 years). Four patients (4.3\%) had a confirmed dislocation. The four patients who had confirmed dislocation had the following characteristics: $28 \mathrm{~mm}$ femoral head size, age over 60 years, two posterior approaches and three females, although not statistically significant.
\end{abstract}

Conclusion: The outcomes of THA in patients with NOF fractures can be favourable and provide good long-term prosthesis survival. We report on low dislocation rate post total hip replacement for intra-capsular NOF fractures.

Level of evidence: Level 4

Key words: neck of femur fractures, total hip replacement, dislocation rate, risk factors, South Africa

Citation: Shituleni S, Maqungo S. Displaced intracapsular neck of femur fractures: dislocation rate after total hip arthroplasty. SA Orthop J 2018;17(1):30-34. http://dx.doi.org/10.17159/2309-8309/2018/v17n1a4

Editor: Prof Anton Schepers, University of the Witwatersrand

Received: April 2016 Accepted: April 2017 Published: March 2018

Copyright: (c) 2018 Shituleni S, et al. This is an open-access article distributed under the terms of the Creative Commons Attribution Licence, which permits unrestricted use, distribution and reproduction in any medium, provided the original author and source are credited.

Funding: No external funding was received.

Conflict of interest: The authors have no conflicts of interest to declare. 


\section{Introduction}

Primary total hip replacement (THR) is suggested for treatment of displaced neck of femur (NOF) fractures in patients with preexisting arthrosis of the hip or if they expect a high level of activity. Dislocation is one of the most common orthopaedic complications after primary total hip arthroplasty (THA). ${ }^{1}$ Dislocation is associated with high morbidity and increased cost for the patient. Dislocated THRs have worse outcomes compared to THRs that do not dislocate. The two-year survival rate for the dislocated THR is slightly over $50 \% .^{2}$

Improved surgical techniques and the evolution of implant design have lowered the dislocation rate after hip arthroplasty surgery for treatment of fractured NOF to approximately $1-5 \%$. In a multicentre prospective randomised trial, Rogmark et al. reported a $6 \%$ failure rate for total hip arthroplasty and a $43 \%$ failure rate for open reduction and internal fixation. ${ }^{3}$ Dislocation rate for total hip arthroplasty was 8\% (4.2\% recurrent dislocations) in the same study with similar one-year mortality of $13 \%$ between the THA and internal fixation groups. Previous studies revealed that dislocation rate following total hip arthroplasty in displaced hip fracture is less than 10\%.4-6

The treatment of displaced NOF fractures has evolved but remains controversial. Options for treatment include nonoperative percutaneous fixation; closed reduction and internal fixation; open reduction and internal fixation; and arthroplasty (either hemiarthroplasty or total hip arthroplasty).

Hip joint preservation and avoidance of complications of THA are regarded as advantages by some surgeons. On the other hand, some surgeons favour THA as a treatment modality due to quicker rehabilitation and the avoidance of all complications associated with fracture union and femoral head vascularity. ${ }^{7}$

For patients with appropriate indications for THA for treatment of acute NOF fracture, THA can provide good outcomes, it costs less, and has long-term survival of the prosthesis. ${ }^{8}$ Total hip arthroplasty for treatment of NOF fracture has a lower failure rate compared to open reduction and internal fixation. In THA, functional recovery of the patients was good. It had lower revision rates, but dislocation rates have been high, ranging between 6 and 22\%. ${ }^{9}$

Various factors influence the risk of dislocation after THA. These are patient-related factors such as age, sex, diagnosis, alcoholism, dementia, neuromuscular and cognitive disorders, and psychosis; or surgical risk factors such as surgical approach, component positioning, soft tissue tension, head size, impingement and liner profile. ${ }^{10-12}$ Femoral head sizes of larger diameters increase the head-neck ratio. Range of motion is increased before impingement, therefore reducing the dislocation rate. They have a higher friction moment, despite the advantage of an increased jumping distance that lower impingement and risk of dislocation.

For $28 \mathrm{~mm}$ diameter femoral heads the dislocation rate ranges from $0.6 \%$ to $3.6 \%,{ }^{13}$ but even higher for $22 \mathrm{~mm}$ diameter femoral heads that range from $3.8 \%{ }^{13}$ to $18.8 \% .{ }^{14}$ Lower rates are reported for the $32 \mathrm{~mm}$ diameter femoral heads, $0.5 \%$ and $0.0 \%$ for $38 \mathrm{~mm}$ diameter. ${ }^{15} \mathrm{In}$ a recent study, femoral heads bigger than $36 \mathrm{~mm}$ resulted in a drastic decrease in the dislocation rate following THA when compared to head sizes of less than $36 \mathrm{~mm}^{16}$

\section{Rationale and problem identification}

THA performed for NOF fracture has a higher risk of dislocation than THA done for hip arthrosis. Larger femoral head sizes have a lower incidence of dislocation. However, the dislocation rate is not known in South Africa. Furthermore, the factors that may be associated with an increased risk of dislocation in the South African context are not known.

\section{Aims and objectives}

The aim of this study was to determine the prevalence and risk factors of dislocation following total hip arthroplasty for treatment of acute NOF fractures at our level 1 hospital during the period of 2006 to 2012. In order to achieve this aim, the objectives of the study were:

- to estimate the number of dislocations following total hip arthroplasty during the period 2006 to 2012

- to investigate the association between femoral head size and the risk of dislocation after THA

\section{Methods}

\section{Design}

This study was a retrospective review of records of patients who had a total hip arthroplasty for NOF fractures during the period 2006-2012.

\section{Setting}

The study was conducted at a level 1 university hospital.

\section{Inclusion and exclusion criteria}

All total hip arthroplasties for fractured NOF during 2006-2012 were included. Patients who did not have a minimum of oneyear follow-up were contacted to confirm if they had dislocated. All the patients with pathological fractures, extra-capsular fractures, failed open reduction and internal fixation, and patients with less than 3 months' follow-up were excluded from this study.

\section{Measurements}

A list of patients' names was obtained from the arthroplasty registry and the information in the patients' medical records and radiographs reviewed. Hip dislocation was the end point of the review. We counted the total number of patients with confirmed dislocations. Femoral head sizes were recorded.

\section{Statistical analysis}

All numerical data were tested for normality using the Shapiro Wilks test. For normally distributed data, means and standard deviations were described. Where data were skewed, medians and interquartile ranges (IQR) were described. For categorical data, frequencies and proportions were described. The dislocations were counted and expressed as a proportion of the total number of participants. For risk factors, binary logistic regression, with dislocation (yes/no) as the outcome, was used to report odds ratios, $95 \%$ confidence intervals and $p$-values. Multivariate analysis was attempted although the low sample size and low number of dislocations was a limiting factor.

\section{Results}

One-hundred-and-seven patients treated with THA for NOF fracture were identified. Fifteen (14\%) patients were unsuitable for analysis. A total of 92 patients were therefore included in this study. The median age at the time of surgery was 64.4 years (inter-quartile range or IQR 57.9-72.0). The maleto-female ratio of patients included in the study was 37(40.2\%):55(59.8\%). The median delay to surgery for THA was three days (IQR 2-6) days. One patient, who had a 63-day delay before THA, was admitted to a different hospital prior to transfer to our unit. The median follow-up period was 18.3 months (range: 3-51.6) (Table I). 
Table I: Demographic characteristics

\begin{tabular}{|c|c|c|}
\hline & & Frequency (\%) \\
\hline \multirow{2}{*}{ Gender } & Female & $55(59.8)$ \\
\hline & Male & $37(40.2)$ \\
\hline \multirow{2}{*}{$\begin{array}{l}\text { Side of } \\
\text { operation }\end{array}$} & Right & $44(47.8)$ \\
\hline & Left & $48(52.2)$ \\
\hline \multirow{2}{*}{$\begin{array}{l}\text { Delay to } \\
\text { surgery (days) }\end{array}$} & Median = 3 & \\
\hline & $\mathrm{IQR}=2$ to 6 & \\
\hline \multirow{2}{*}{$\begin{array}{l}\text { Age at time of } \\
\text { surgery (years) }\end{array}$} & Median = 64.4 & \\
\hline & $\mathrm{IQR}=57.9$ to 72.0 & \\
\hline \multirow{2}{*}{$\begin{array}{l}\text { Follow-up } \\
\text { (months) }\end{array}$} & Mean = 18.3 & $18.3(3-51.6)$ \\
\hline & Range $=3.0-51.6$ & \\
\hline \multirow{4}{*}{$\begin{array}{l}\text { Implant } \\
\text { articulation }\end{array}$} & \multirow{2}{*}{$\begin{array}{l}\text { Hard-on-soft } \\
\text { bearing couples }\end{array}$} & Metal-on-polyethylene 76 \\
\hline & & Ceramic-on-polyethylene 0 \\
\hline & \multirow{2}{*}{$\begin{array}{l}\text { Hard-on-hard } \\
\text { bearing couples }\end{array}$} & Metal-on-metal 6 \\
\hline & & Ceramic-on-ceramic 10 \\
\hline
\end{tabular}

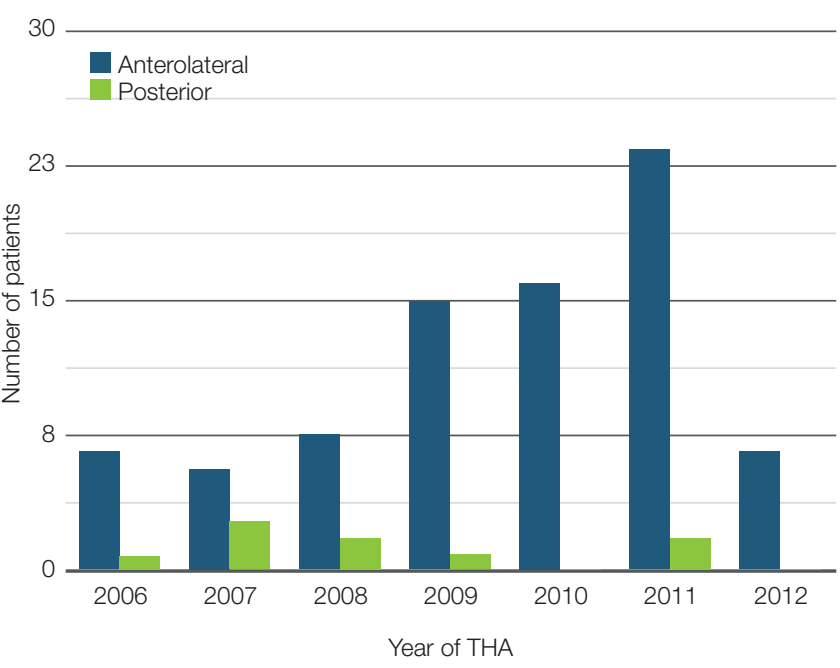

Figure 1. Preferred surgical approach. Surgical exposure of the hip for THA can be done through the anterior approach, anterolateral approach, direct lateral approach and posterior approach.

The preferred surgical approach for THA was anterolateral, with 83 (90.2\%) patients (Figure 1). The posterior approach was occasionally utilised, with only nine $(9.8 \%)$ patients operated through this approach.

The most frequently used head sizes were $28 \mathrm{~mm}$ and $32 \mathrm{~mm}$; with nine $(9.8 \%)$ patients having the $28 \mathrm{~mm}$ femoral head implanted, 32 (34.8\%) the $32 \mathrm{~mm}, 16$ (17.4\%) $36 \mathrm{~mm}$ while five (5.4\%) patients had larger than $36 \mathrm{~mm}$ femoral heads (Figure 2).

A total of $16(17.4 \%)$ THA were hard-on-hard coupling (6 [6.5\%] metal-on-metal and ten [10.9\%] ceramic-on-ceramic), whereas the rest (76 [82.6\%]) were metal-on-polyethylene.

\section{Prevalence of dislocations}

Four patients (4.3\%) had confirmed dislocations within the first year following THA (Table II). The dislocations occurred after days 19, 39, 94 and 249 after discharge from hospital. The dislocations were verified through a review of patient records, radiographs and interviews with patients. There were no recurrent dislocations following reduction in the three patients and revision for the one patient. No other adverse events were recorded during follow-up of these patients.

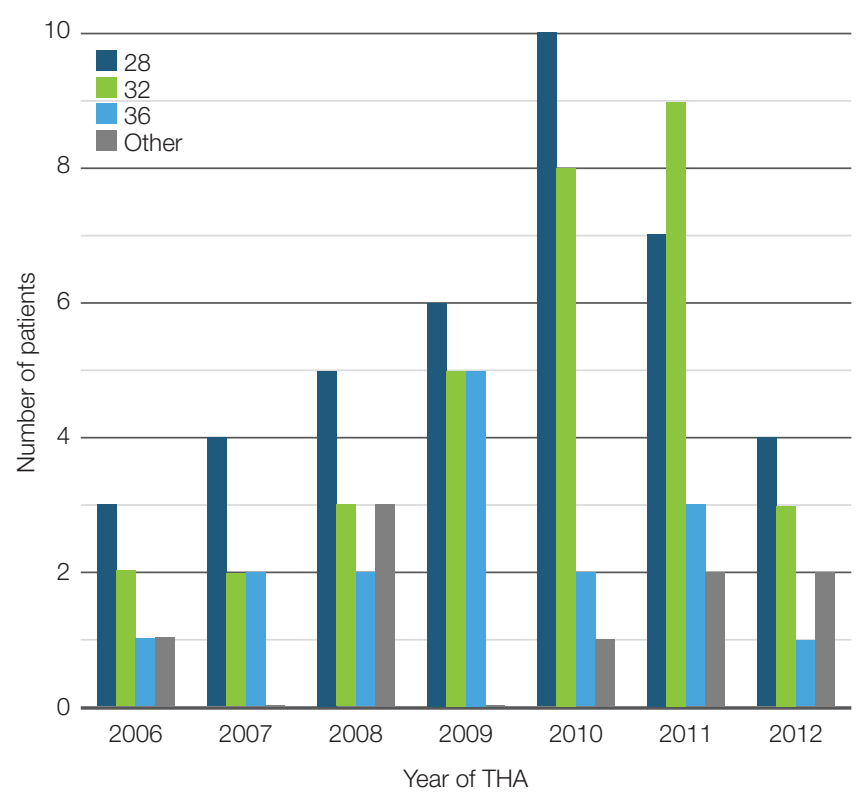

Figure 2. Most frequently used head sizes. Femoral head sizes vary between $22 \mathrm{~mm}$ and $60 \mathrm{~mm}$. The size of the head implanted is dependent on the size of the acetabular cup. This varies between patients.

\section{Risk factors associated with dislocation}

All four hips that dislocated following THA for fractured NOF had a $28 \mathrm{~mm}$ articulation. Their median age was 63 years. Three of the four dislocations were female. With respect to surgical approach, two of the patients had anterolateral approaches while the other two had posterior approaches.

Being female was associated with increased risk of dislocation, but this did not show statistical significance $(\mathrm{OR}=0.01 ; 95 \% \mathrm{Cl}$ 0.001-0.87, $p=0.044)$. Bigger head sizes were associated with reduced risk for dislocation, although this did not reach statistical significance $(\mathrm{OR}=0.27 ; 95 \% \mathrm{Cl} 0.06-1.19, \mathrm{p}=0.083)$. There was no association between either age or delay to surgery and risk of dislocation (Table III). Due to the small number of the dislocations that occurred, and the small sample size, these results need to be treated with caution.

\section{Discussion}

Literature review showed only a few papers had analysed the treatment of NOF fractures with THA and risk factors associated with dislocation. There is strong support in the literature to treat displaced intracapsular NOF fractures with THA. ${ }^{17}$ Hemiarthroplasty provides superior outcomes compared to fixation, but THA has been shown to have advantages over both hemiarthroplasty and fixation. ${ }^{17,18}$ Bhandari et al. in their systemic review and analysis showed that though THA may increase surgical mortality, it reduces the need for reoperation. ${ }^{17}$

Due to the reported high dislocation rate and cost associated with THA some surgeons avoid performing THA, and thus there is no consensus for the treatment of displaced intracapsular NOF fractures. There are two large multicentre randomised trials underway currently (FAITH and HEALTH). The FAITH trial (Fixation Using Alternative Implants for the Treatment of Hip Fractures) compares sliding hip screws and cancellous screws on revision surgery rates for the treatment of femoral neck fractures. The HEALTH trial (Hip Fracture Evaluation with Alternative of Total Hip Arthroplasty versus hemiarthroplasty) compares THA and hemiarthroplasty. Once these studies are completed, they should provide answers to the current controversy of optimal treatment of NOF fractures. 
Table II: Patient characteristics with hip dislocation following THA for NOF fracture

\begin{tabular}{|c|c|c|c|c|c|c|}
\hline Patient & Head size $(\mathbf{m m})$ & Age (years) & Sex (F:M) & $\begin{array}{c}\text { 1st dislocations (no. of } \\
\text { days after surgery) }\end{array}$ & $\begin{array}{c}\text { Surgical approach } \\
\text { (Yes/No) }\end{array}$ \\
\hline 1 & 28 & 69 & F & 19 & Anterolateral & No \\
\hline 2 & 28 & 61 & M & 249 & Posterior & Anterolateral \\
\hline 3 & 28 & 63 & F & 94 & Posterior & No \\
\hline 4 & 28 & 74 & F & 39 & & Pes \\
\hline
\end{tabular}

Table III: Head size and dislocation

\begin{tabular}{|l|c|c|c|c|}
\hline \multirow{2}{*}{} & \multicolumn{2}{|c|}{ Univariate analysis } & \multicolumn{2}{c|}{ Multivariate analysis } \\
\cline { 2 - 5 } & OR (95\% Cl) & P-value & OR $(95 \%$ Cl) & 0.299 \\
\hline Age & $1.03(0.93-1.14)$ & 0.547 & $1.15(0.88-1.51)$ & 0.044 \\
\hline Sex (female vs male) & $0.57(0.08-4.25)$ & 0.582 & $0.01(0.001-0.87)$ & 0.256 \\
\hline Delay & $0.78(0.44-1.37)$ & 0.385 & $0.58(0.23-1.48)$ & 0.083 \\
\hline Head size (bigger vs small) & $0.57(0.29-1.12)$ & 0.105 & $0.27(0.06-1.19)$ & \\
\hline
\end{tabular}

Internal fixation for fractured NOF fracture may carry significant complications such as osteonecrosis, leading to avascular necrosis, implant failure and non-union. ${ }^{17}$ The benefit of THA for displaced NOF fractures outweighs the risk of dislocation following THA.

A total of 92 patients were included in this study. Fifteen patients (in addition to the 92) were excluded due to inadequate recording-keeping of pre-operative assessment, incomplete surgery data records, pathological fracture and previous ORIF. The median age at the time of surgery was 64 years. The study included 55 (59.8\%) females and 37 (40.2\%) males. Hailer et al. showed that age did not influence the risk of revision due to dislocation; however, they reported that female patients had a lower risk of dislocation. ${ }^{19}$ Rogmark et al. as well as Lee et al. reported on higher dislocation rate in elderly patients. 3,20 The average follow-up in this study was 18.3 months with a minimum of 3 months' follow-up. Previous authors reported high incidence of dislocation within the first 3 months and an overall high dislocation rate within the first year following THA. ${ }^{10,11,13}$ Most studies showed a variation in follow-up, some slightly longer. This is probably due to the follow-up protocols of different units, and some patients being discharged earlier if there were no concerns. The minimum follow-up period in this study is similar to most other studies. Socio-economic situations might have forced some patients not to follow up if they had no complaints.

In this study, four patients (4.3\%) had confirmed dislocation. This is lower than that reported by many previous researchers. For example Bhandari et al. (6.9\%), Keating et al. (8.6\%), Baker et al. (7.5\%), McKinley et al. (9\%), Rogmark et al. (8\%) and Lee et al. (10\%) all found higher rates of dislocation.3,17,18,20-22 However, one study, Blomfeldt et al. reported a lower (2\%) dislocation rate compared to our results. ${ }^{23}$

Three of the four patients had a successful closed reduction and no further complications were reported. One patient required revision surgery and a change of component orientation. All four dislocations had smaller femoral head sizes (28 mm), which is consistent with what has been reported previously. In particular, Berry et al. reported on a higher dislocation rate in patients who had smaller femoral head size and posterior approach. ${ }^{13}$ Hailer et al. reported higher dislocation rates with minimally invasive procedures compared to the anterolateral approach. ${ }^{19}$ Greater tuberosity non-unions are associated with higher dislocation rates. ${ }^{24}$ Eftekhar et al. reported on the association of surgeon experience and dislocation rates. ${ }^{25}$ Younger surgeons and trainees had a slightly higher incidence of dislocation compared to experienced surgeons. Although the sample size was not enough to allow a multivariate regression, one possible explanation for this is that the jumping distance is decreased in smaller head diameters, predisposing patients to dislocation. Two patients (50\%) had the posterior approach. The male-to-female ratio was 1:3 for the dislocations. Although all the patients in our study were older than 60 years, we were unable to test the statistical significance of age as a risk factor for dislocation due to the small sample size.

All four dislocations were within the first year of the index THA. There are no reported reasons for the exact cause of early dislocations. This is likely due to the time required for the healing of the capsule and soft tissues.

\section{Limitations of the study}

The major weakness of our study is that it was not randomised. We recruited a small cohort of retrospective THAs, although this was over a significant period of time, the population group presenting with NOF fractures suitable for THA is smaller. Younger patients are treated by reduction and fixation, whereas most of the elderly who are not independently mobile, with multiple comorbidities and cognitive impairment, are treated with hemiarthroplasty.

We were unable to report on factors such as cognitive status, neuromuscular disorders, soft tissue tensioning and impingement for the patients that dislocated. This is mainly due to the lack of appropriate record-keeping.

Implant neck geometries were not recorded to determine the head-neck ratio. These are factors that may affect the dislocation risk independently.

\section{Conclusion}

Our early dislocation rate of $4.3 \%$ is within the published results and shows that primary THA is an acceptable and safe option for displaced intracapsular NOF fractures in active patients. Larger femoral head sizes may have a lower dislocation rate. More rigorous, better-designed studies are needed to investigate risk factors for dislocation in our setting. 


\section{Compliance with ethics guidelines}

This study was approved by the Human Research Ethics Committee (HREC REF: 632/2012). The study adheres to the Helsinki Declaration of 2008.

\section{References}

1. Mccollum De, Gray WJ. Dislocation after total hip arthroplasty causes and prevention. Clin Orthop 1990;261:159-70.

2. Sah AP, Estok DM,2nd. Dislocation rate after conversion from hip hemiarthroplasty to total hip arthroplasty. J Bone Joint Surg Am 2008 Mar;90(3):506-16.

3. Rogmark C, Johnell O. Primary arthroplasty is better than interna fixation of displaced femoral neck fractures: a meta-analysis of 14 randomized studies with 2,289 patients. Acta Orthopaedica 2006;77(3):359-67.

4. Kristiansen B, Jørgensen L, Hölmich P. Dislocation following tota hip arthroplasty. Archives of orthopaedic and traumatic surgery 1985;103(6):375-77.

5. Gregory R, Wood D, Stevens J. Treatment of displaced subcapital femoral fractures with total hip replacement. Injury 1992;23(3): 168-70.

6. Squires B, Bannister G. Displaced intracapsular neck of femur fractures in mobile independent patients: total hip replacement or hemiarthroplasty? Injury 1999;30(5):345-48.

7. Hunter $\mathrm{G}$. Treatment of fractures of the neck of the femur. Can Med Assoc J 1977 Jul 9;117(1):60-61.

8. Lee BP, Berry DJ, Harmsen WS, Sim FH. Total hip arthroplasty for the treatment of an acute fracture of the femoral neck: long-term results. J Bone Joint Surg Am 1998 Jan;80(1):70-75.

9. Ravikumar KJ, Marsh G. Internal fixation versus hemiarthroplasty versus total hip arthroplasty for displaced subcapital fractures of femur -13 year results of a prospective randomised study. Injury 2000;31(10):793-97.

10. Woo RY, Morrey BF. Dislocations after total hip arthroplasty. J Bone Joint Surg Am 1982 Dec;64(9):1295-306.

11. Meek RM, Allan DB, McPhillips G, Kerr L, Howie CR. Epidemiology of dislocation after total hip arthroplasty. Clin Orthop Relat Res 2006 Jun;447:9-18.

12. Khatod M, Barber T, Paxton E, Namba R, Fithian D. An analysis of the risk of hip dislocation with a contemporary total joint registry. Clin Orthop Relat Res 2006 Jun;447:19-23.

13. Berry DJ, von Knoch M, Schleck CD, Harmsen WS. Effect of femoral head diameter and operative approach on risk of dislocation after primary total hip arthroplasty. J Bone Joint Surg Am 2005 Nov;87(11):2456-63.

14. Padgett DE, Lipman J, Robie B, Nestor BJ. Influence of total hip design on dislocation: a computer model and clinical analysis. Clin Orthop Relat Res 2006 Jun;447:48-52.

15. Peters CL, McPherson E, Jackson JD, Erickson JA. Reduction in early dislocation rate with large-diameter femoral heads in primary total hip arthroplasty. J Arthroplasty 2007;22(6):140-44.

16. Jameson SS, Lees D, James P, Serrano-Pedraza I, Partington PF, Muller SD, et al. Lower rates of dislocation with increased femoral head size after primary total hip replacement: a five-year analysis of NHS patients in England. J Bone Joint Surg Br 2011 Jul;93(7): 876-80.

17. Baker RP, Squires B, Gargan MF, Bannister GC. Total hip arthroplasty and hemiarthroplasty in mobile, independent patients with a displaced intra-capsular fracture of the femoral neck. A randomized, controlled trial. J Bone Joint Surg Am 2006 Dec;88(12):2583-89.

18. Keating JF, Grant A, Masson M, Scott NW, Forbes JF. Randomized comparison of reduction and fixation, bipolar hemiarthroplasty, and total hip arthroplasty. Treatment of displaced intracapsular hip fractures in healthy older patients. J Bone Joint Surg Am 2006 Feb;88(2):249-60.

19. Hailer NP, Weiss RJ, Stark A, Kärrholm J. The risk of revision due to dislocation after total hip arthroplasty depends on surgical approach, femoral head size, sex, and primary diagnosis: an analysis of 78,098 operations in the Swedish Hip Arthroplasty Register. Acta Orthopaedica 2012;83(5):442-48.

20. Lee BP, Adams RA, Morrey BF. Polyethylene wear after total elbow arthroplasty. J Bone Joint Surg Am 2005 May;87(5):1080-87.
21. Bhandari M, Devereaux PJ, Swiontkowski MF, Tornetta P, 3rd, Obremskey W, Koval KJ, et al. Internal fixation compared with arthroplasty for displaced fractures of the femoral neck. A meta-analysis. J Bone Joint Surg Am 2003 Sep;85-A(9):1673-81.

22. McKinley JC, Robinson CM. Treatment of displaced intracapsular hip fractures with total hip arthroplasty: comparison of primary arthroplasty with early salvage arthroplasty after failed internal fixation. J Bone Joint Surg Am 2002 Nov;84-A(11):2010-15.

23. Blomfeldt R, Tornkvist H, Ponzer S, Soderqvist A, Tidermark J. Comparison of internal fixation with total hip replacement for displaced femoral neck fractures. Randomized, controlled trial performed at four years. J Bone Joint Surg Am 2005 Aug; 87(8):1680-88

24. Callaghan JJ. Mobile-bearing knee replacement: clinical results: a review of the literature. Clin Orthop 2001;392:221-25.

25. Eftekhar NS, Demarest RJ. Principles of total hip arthroplasty. CV Mosby Company; 1978. 